\title{
Correction to: Full title: peripheral venous catheter complications in children: predisposing factors in a multicenter prospective cohort study
}

Rim Ben Abdelaziz ${ }^{1,2,3,8^{*}}$, Habiba Hafsi ${ }^{1}$, Hela Hajji ${ }^{1}$, Hela Boudabous ${ }^{1,2,3}$, Amel Ben Chehida ${ }^{1,2,3}$, Ali Mrabet ${ }^{2,4}$, Khadija Boussetta ${ }^{2,5}$, Sihem Barsaoui ${ }^{2,6}$, Azza Sammoud ${ }^{2,7}$, Mourad Hamzaoui ${ }^{2,8}$, Hatem Azzouz ${ }^{1,2,3}$ and Néji Tebib ${ }^{1,2,3}$

\section{Correction}

Following publication of the original article [1], one of the authors flagged that the title of the article was submitted (incorrectly) with "Full title:" at the beginning.

As such, please be advised that the correct title is: Peripheral venous catheter complications in children: predisposing factors in a multicenter prospective cohort study.

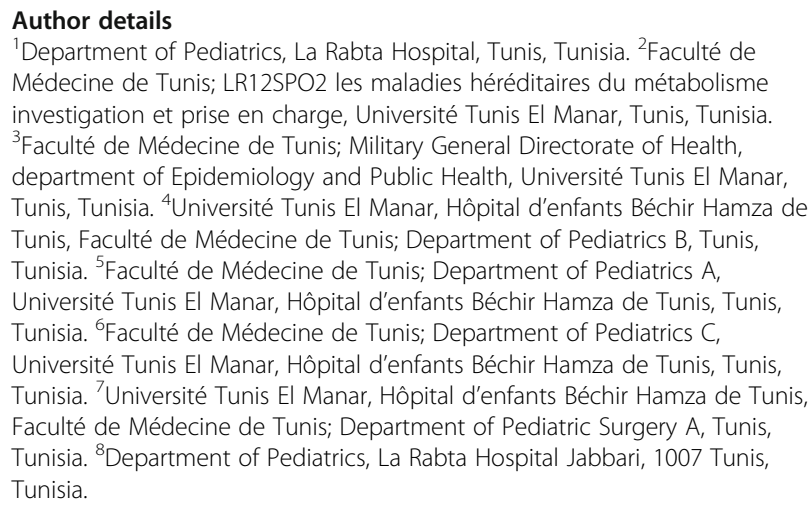

Published online: 24 September 2018

\section{Reference}

1. Ben Abdelaziz R, et al. Full title: peripheral venous catheter complications in children: predisposing factors in a multicenter prospective cohort study. BMC pediatrics. 2017;17:208. https://doi.org/10.1186/s12887-017-0965-y.

\footnotetext{
*Correspondence: rimelair@gmail.com; rimbenabdelaziz@yahoo.fr

1 Department of Pediatrics, La Rabta Hospital, Tunis, Tunisia

${ }^{2}$ Faculté de Médecine de Tunis; LR12SPO2 les maladies héréditaires du métabolisme investigation et prise en charge, Université Tunis El Manar,

Tunis, Tunisia
} 